\title{
A review of documents prepared by international organizations about influenza pandemics, including the 2009 pandemic: a bibliometric analysis
}

Feng Liang ${ }^{1}$, Peng Guan ${ }^{1}$, Wei Wu' ${ }^{1}$, Jing Liu', Ning Zhang ${ }^{1}$, Bao-Sen Zhou ${ }^{1}$ and De-Sheng Huang ${ }^{1,2^{*}}$ (D)

\begin{abstract}
Background: World Health Organization (WHO), the World Bank, UN System Influenza Coordination (UNSIC) and other international organizations released a series of documents to fight against the influenza pandemic. Those documents have great significance on guiding influenza pandemic preparedness and responses and providing a multilevel, multi-directional influenza pandemic prevention and control network for their member countries. This study focuses on the above-mentioned influenza pandemic preparedness guidelines with the aim of exploring the roles of the society, defining the relationship of different interventions and evaluating the planning on influenza pandemic preparedness.
\end{abstract}

Methods: Documents about pandemic influenza preparedness were retrieved from the official websites of the following three international organizations, World Health Organization (WHO), the World Bank, UN System Influenza Coordination (UNSIC) with the key words 'pandemic', 'influenza' and the Boolean combinations of these words as the retrieval strategy. Guidelines, research study and meeting reports were included in the study. The categories of the ministries/departments involved and their roles/responsibilities in pandemic influenza preparedness were summarized. Word frequency of selected vocabularies about pandemic influenza preventive measures were collected from the documents and the correlations between the word frequency of these measures were analyzed. Ochiai coefficient was employed to show the correlation between the word vocabularies.

Results: A total of 38 records on the topic of pandemic influenza preparedness were included. The responsibilities of the whole-of-society mentioned in the international organizations' documents varied across the 2009 influenza pandemic period. Meanwhile, it had been emphasized that a comprehensive influenza prevention and control plan in every sector should be developed and evaluated. Because various measures were emphasized in the guidelines after 2009 pandemic influenza, the correlations between the word frequencies of the various influenza preventive measures became stronger after the pandemic influenza.

Conclusions: Responsibilities of ministries of education, ministries of energy, ministries of agriculture and animal health, ministries of communication and the business sector in the pandemic influenza preparedness were described more comprehensively in the international organizations' documents in 2017. Better understanding the variations of the guidelines delivered by international organizations would be useful for the member countries to strengthen their influenza control network.

Keywords: Pandemic influenza, H1N1, Sectors, Intervention, International organization

\footnotetext{
* Correspondence: dshuang@cmu.edu.cn

'Department of Epidemiology, School of Public Health, China Medical University, Shenyang 110122, China

${ }^{2}$ Department of Mathematics, School of Fundamental Sciences, China

Medical University, Shenyang 110122, China
}

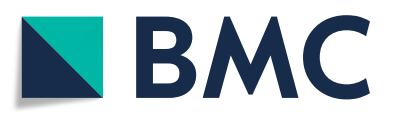

(c) The Author(s). 2018 Open Access This article is distributed under the terms of the Creative Commons Attribution 4.0 International License (http://creativecommons.org/licenses/by/4.0/), which permits unrestricted use, distribution, and reproduction in any medium, provided you give appropriate credit to the original author(s) and the source, provide a link to the Creative Commons license, and indicate if changes were made. The Creative Commons Public Domain Dedication waiver (http://creativecommons.org/publicdomain/zero/1.0/) applies to the data made available in this article, unless otherwise stated. 


\section{Background}

As the unpredictable but recurrent events, influenza pandemics have rapid also severe consequences on human health and the economy in all parts of the world [1]. The influenza $A(H 1 N 1) 2009$ pandemic was the first pandemic influenza in the 21st century, the outbreak of the new $\mathrm{A}(\mathrm{H} 1 \mathrm{~N} 1) \mathrm{pdm} 09$ virus triggering worldwide attention to influenza [2]. During the 2009 pandemic, over 600,000 confirmed cases were reported having been infected $\mathrm{A}(\mathrm{H} 1 \mathrm{~N} 1)$ pdm09 virus worldwide [3], more than 208 countries and territories have been affected [4].

The advance planning and preparedness play important roles in mitigating the impact of an influenza pandemic [5-7]. Previous reports have indicated that the significant improvements in influenza pandemic preparedness between 2008 and 2012 in Central America [8] and the preparedness planning might strengthen the collective, multilevel responses to future public health crises [9]. The investment in pandemic influenza preparation has been proved to contribute the improvement of capacity ability in health systems in Asia [10].

World Health Organization (WHO), the World Bank, UN System Influenza Coordination (UNSIC) and other international organizations released a series of documents to fight against the influenza pandemic. Those documents have great significance on guiding influenza pandemic preparedness and responses and providing a multilevel, multi-directional pandemic prevention and control network for their member countries.

International organizations have been central to handling different aspects of pandemic influenza preparedness, from macro-level policy design to micro-level specific preventive measures. However, despite their importance, we lack a systematic understanding of changes of the guidelines or documents regarding pandemic influenza preparedness across the 2009 pandemic. In this context, this article seeks to clarify the roles and responsibilities of each sector involving in pandemic influenza preparedness via the content analysis of the guidelines, the changes of the guidelines across the 2009 pandemic and the theme of assessment that mentioned in the documents. Based on our findings, it is promising for the member countries of the international organizations to establish the framework to take stock of influenza pandemic readiness and address the coordination challenges.

\section{Methods}

\section{Inclusion and exclusion criteria}

The present review focused on the documents released by the international governmental organizations within the UN system about pandemic influenza preparedness. The inclusion criteria of the international organizations were as follows, a) the international organization was within the UN system; b) the international organization provided leadership, financial assistance, cooperation and coordination for pandemic influenza preparedness, c) the international organization dealt with global challenges of influenza control in the whole population. The exclusion criteria of the international organizations were a) the regional office of the international organization, b) main attention on animal health, such as World Organization for Animal Health, and c) main attention on part of the whole population, such as UNICEF.

On the basis of the above inclusion criteria and restrictions, World Health Organization (WHO), The World Bank, UN System Influenza Coordination (UNSIC) Office were included in the study. WHO is the directing and coordinating authority on international health within the United Nations' system; the mission of the World Bank is to end extreme poverty and promote shared prosperity; the primary purpose of UNSIC Office is to ensure cooperation and coordination within the UN system in support of different initiatives underway to address the avian flu epidemic and the threat of a human pandemic.

Documents about pandemic influenza preparedness were retrieved from the official websites of these three international organizations with the key words 'pandemic', 'influenza' and the Boolean combinations of these words as the retrieval strategy. Guidelines, research study and meeting reports were included in the study. The last search date was July 3, 2017. The full text of each document was downloaded and screened according to the information obtained from the title, abstract or main text. Only the documents reporting pandemic influenza preparedness were included. News and comments were excluded from the analysis.

\section{Theme summary and correlation analysis}

After reading the full text, the basic information of the included documents was described, the categories of the ministries/departments involved and their roles/responsibilities in pandemic influenza preparedness were summarized. In the process of vocabularies extraction, the initial vocabularies were determined by consulting experts, and the final vocabularies that were submitted to the word frequency analysis were determined due to their existence in equal to and more than half of the documents. To accurately extract and count the bibliographic information from worldwide international websites, the co-occurrence matrix was generated and basic data were submitted to subsequent statistical analysis. To ensure the reliability, two authors (FL and PG) independently screened each document and the overlapped words were decided first and the differences were settled after discussion, the information extraction process was checked by a third reviewer (DSH). 


\section{Statistical analysis}

Word frequency of selected vocabularies about pandemic influenza preventive measures were collected from the documents and the correlations between the word frequency of these measures were analyzed. In order to reduce the influence of the maximum or minimum of frequency between the vocabularies on the correlation, Ochiai coefficient was employed to show the correlation between the two vocabularies with the calculation formula Ochiai coefficient $=\frac{A B}{\sqrt{A^{*} B}}$, where $A B$ is the frequency of co-occurrence between words A and B; A is the frequency of occurrence of the word $A$; $B$ is the frequency of occurrence of the word B. The calculation was done by using the software Statistical Product and Service Solutions (SPSS 12.0 for windows, SPSS Inc., Chicago, IL, USA).

\section{Results}

Documents search and the characteristics of the included documents

Based on our search strategy, a total of 89 records on the topic of pandemic influenza preparedness were first identified from the official websites of these three international organizations. The major paths to retrieve the included documents from the three international organizations' official websites were as follows: WHO (http:// www.who.int/en/) $>$ Health topic >Influenza >Public health preparedness $>$ List of documents on Pandemic; UNSIC (http://www.un-influenza.org/) > topic > Pandemic Preparedness Guidance for the UN System; UNSIC $>$ Resources > key documents; The World Bank $>$ What We Do $>$ Development Knowledge $>$ Research \& Publication. There were 38 records included in the bibliometric analysis, besides WHO, UNSIC and the World Bank, all the involved organizations included FAO, ICAO, ILO, IOM, OCHA, OIE, UNDP, UNFPA, UNHCR, UNICEF, UNWTO, WFP, ADPC, K. I. Asia and GTZ. The flowchart of the literature search and selection process according the inclusion criteria is shown in Fig. 1.

The basic information of the included 38 documents are described from six aspects: source, author, publishing date, title, theme, number of pages in its original format. The earliest document was released in 2004, and the latest document was released in 2017. There were 13 documents before the influenza pandemic (before April 2009), 6 documents during the pandemic period (April 2009 to August 2010), 17 documents after the pandemic (after August 2010), and the publishing dates of two documents could not be identified. The length of the documents in this field is also a good indicator of international efforts to improve influenza pandemic preparedness. The length of each document was judged by the number of pages which ranged from 1 to 180 and the median of pages was 44.5. The characteristics of the included documents are presented in Additional file 1: Table S1.

\section{Whole-of-society pandemic readiness}

WHO first proposed whole-of-society pandemic readiness in WHO guidelines for pandemic influenza preparedness and response in 2009 [7]. Detailed information on the whole-of-society approach were provided in the documents. After consulting a range of experts their opinions of pandemic influenza and discussion, WHO developed the recommendations on pandemic influenza preparedness, which was not evidence-based [11]. WHO released Pandemic Influenza Risk Management-WHO Interim Guidance in 2013 and Pandemic Influenza Risk Management in 2017, which took account of lessons and

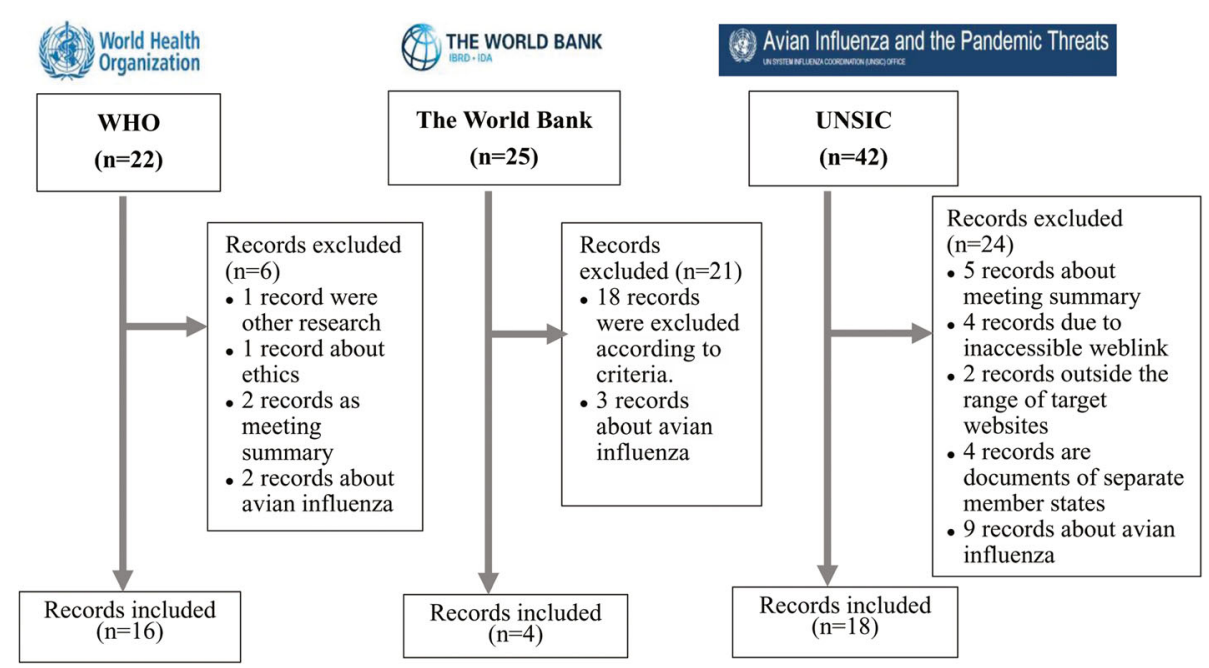

Fig. 1 Flow chart of document search and selection process about pandemic influenza preparedness 
experience learnt from the influenza A(H1N1) 2009 pandemic and of other developments in relevant fields $[5,6]$. The roles and responsibility of whole-of-society across the influenza pandemic period are shown in Table 1, where the differences of the documents' context between 2009 and 2017, are described. The roles and responsibilities in 2017 are described more comprehensively for the following sectors: ministries of education, ministries of energy, ministries of agriculture and animal health, ministries of communication and the business sectors. Meanwhile, it has been emphasized that a comprehensive influenza prevention and control plan in every sector should be developed and evaluated.

Whole-of-society pandemic readiness are also emphasized in the World Bank and UNSIC. WHO elaborated on it while the World Bank and UNSIC did not. The World Bank focused on the source, allocation and disbursement of funding for the pandemic influenza preparedness, and shared some useful lessons on "good health at low cost" in Sri Lanka [12]. UNSIC paid attention to all aspects of flu such as funding, risk assessment, medical guidance, country coordination, urgent support, simulation exercise and etc.

\section{Words frequency analysis of the intervention on pandemic influenza}

After summarizing the vocabularies on prevention and control measures across the influenza pandemic period in the included documents, the frequencies of selected vocabularies were analyzed and sent to the correlation analysis. Two documents were excluded in the word frequency analysis due to the unknown publication date. After first round of vocabulary screening, 6 words were excluded due to their absence in more than half of the 36 included documents to get a more accurate result. The final included vocabularies and the co-occurrence of word frequency in the three phases are indicated in Table 2. The Ochiai coefficient varies across the pandemics influenza period, 8, 20 and 16 pairs of vocabularies exceed 0.5 in the period that before, during and after pandemic, respectively. Prior to 2009, the focus on influenza that with pandemic potential was mainly on the avian influenza subtype $\mathrm{A}(\mathrm{H} 5 \mathrm{~N} 1)$. Biosecurity was the most important activity before 2009 and the correlations between the word frequencies of the various preventive measures were not strong. During the pandemic (2009-2010), a 'whole-of-society' approach to pandemic influenza preparedness was proposed by WHO in 2009, which resulting in more frequent cooccurrence of the measures in the documents. The following four words' frequencies were closely related to each other: plan, policy, communication and surveillance.

\section{Theme of assessment via content analysis}

Assessment of the prevention and control plan for the pandemic influenza has been mentioned in 10 of the 38 included documents. Among the ten documents, the content is consistent in many aspects, with some differences in the level of detail for the description. Eight documents were released by WHO, focusing on the 'whole-of-society' pandemic readiness; the rest two documents were issued by the World Bank and UNSIC, focusing on the pandemic risk, continued vigilance and investments. Five categories of assessment theme were summarized as follows: assessment of pandemic severity, risk assessment, assessment of national planning, simulation exercises on influenza pandemic responses and effectiveness of public health measures. A summary of the essential content in each category is provided in Table 3.

\section{Discussion}

The comprehensive, coordinated, whole-of-society approach to pandemic preparedness is necessary and crucial to the success of influenza control program [5]. The communities of international organizations have paid increasing attention to bringing member countries, industry and some other stakeholders together to implement the global approach to pandemic influenza preparedness. In this context, the present bibliometric analysis may serve as a starting point for further improvement of international guidance regarding pandemic influenza preparedness. We focused on the official documents of international organizations related to the topic of pandemic influenza control from the quantitative, qualitative and content's points of view and clearly shows the variations of these documents.

The consequences of the pandemic influenza for society and economy will not be more serious, if the governments, businesses, civil society, individuals and families have planned preparedness to how they can maintain their essential services and communicate disease information validly. It has been emphasized by the 'whole-of-society' approach to pandemic influenza preparedness that all sectors of society played significant roles [7]. The differences of the sector responsibilities and measures description that mentioned in the existing guidelines across the pandemic period provided some hints of guidelines modification. Compared to 2009, the roles and responsibilities in 2017 were described more comprehensively in ministries of education, ministries of energy, ministries of agriculture and animal health, ministries of communication and the business sector. Lessons learned from the 2009 H1N1 pandemic influenza action, the roles and responsibilities of the different departments were refined more clearly.

As shown in Table 1, the training items were added for the central government and business sectors in the 
Table 1 The roles and responsibilities of whole-of-society proposed by WHO in 2009 and the addition in 2013 and 2017

\begin{tabular}{|c|c|c|c|}
\hline & Sectors & Roles and responsibility in $2009^{a}$ & $\begin{array}{l}\text { Added roles and responsibility in } \\
2013^{b} \text { and } 2017^{c}\end{array}$ \\
\hline \multirow[t]{10}{*}{ Government } & $\begin{array}{l}\text { Central } \\
\text { government }\end{array}$ & $\begin{array}{l}\text { 1. Leader; } \\
\text { 2. Enact or modify legislation and policies; } \\
\text { 3. Prioritize and guide the allocation and targeting } \\
\text { of resources; } \\
\text { 4. Provide planning information and framework; } \\
\text { 5. Define, oversee, and coordinate preparedness actions. }\end{array}$ & $\begin{array}{l}\text { 1. Conduct training to ensure effective dissemination } \\
\text { at all levels; } \\
\text { 2. Design and implement exercises to } \\
\text { test plans and encourage community mobilization }\end{array}$ \\
\hline & $\begin{array}{l}\text { Ministries of } \\
\text { Transportation }\end{array}$ & $\begin{array}{l}\text { 1. Minimize infection risks and staff absences in vital } \\
\text { transportation plots }\end{array}$ & $\begin{array}{l}\text { 1. Mechanisms for communication and education } \\
\text { of public transportation users }\end{array}$ \\
\hline & $\begin{array}{l}\text { Ministries of } \\
\text { Finance }\end{array}$ & $\begin{array}{l}\text { 1. Maintain essential financial services; } \\
\text { 2. Conduct testing of systemic resilience to pandemic risk }\end{array}$ & $\begin{array}{l}\text { 1. National-level financial planning for pandemic risk } \\
\text { management; } \\
\text { 2. The mechanisms to draw down emergency } \\
\text { funding for interventions should be tested } \\
\text { prior to a pandemic. }\end{array}$ \\
\hline & $\begin{array}{l}\text { Ministries of } \\
\text { Justice }\end{array}$ & $\begin{array}{l}\text { 1. Consider what legal processes could be suspended and make } \\
\text { alternative plans to operate courts during pandemic.; } \\
\text { 2. Minimize the spread of infection in prisons and other institutions } \\
\text { under their authority. }\end{array}$ & $\begin{array}{l}\text { 1. Maintain all essential legal and administrative } \\
\text { operations during a pandemic; } \\
\text { 2. Plans for infection control and risk reduction in } \\
\text { facilities should be tested in conjunction with } \\
\text { the Ministry of Health plans. }\end{array}$ \\
\hline & $\begin{array}{l}\text { Ministries of } \\
\text { Defense }\end{array}$ & 1. Release and mobilize military assets & $\begin{array}{l}\text { 1. Based on Ministry of Health planning assumptions } \\
\text { and risk assessment }\end{array}$ \\
\hline & $\begin{array}{l}\text { Ministries of } \\
\text { Education }\end{array}$ & & $\begin{array}{l}\text { 1. Surveillance of absenteeism in schools; } \\
\text { 2. Linking of school surveillance systems with the } \\
\text { Ministry of Health. }\end{array}$ \\
\hline & $\begin{array}{l}\text { Ministries of } \\
\text { Energy }\end{array}$ & & $\begin{array}{l}\text { 1. Well-developed and well-exercised preparedness } \\
\text { plans; } \\
\text { 2. Alternative plans for energy supplies. }\end{array}$ \\
\hline & $\begin{array}{l}\text { Ministries of } \\
\text { Communication }\end{array}$ & & $\begin{array}{l}\text { 1. Ensure communication channels open at the time } \\
\text { of crises; } \\
\text { 2. Develop a national communication plan }\end{array}$ \\
\hline & $\begin{array}{l}\text { Ministries of } \\
\text { Agriculture and } \\
\text { Animal Health }\end{array}$ & & $\begin{array}{l}\text { 1. Surveillance and monitoring of non-seasonal } \\
\text { influenza viruses; } \\
\text { 2. Decrease the exposure of humans to influenza } \\
\text { viruses at the human-animal ecosystem interface. }\end{array}$ \\
\hline & $\begin{array}{l}\text { Ministries of } \\
\text { Health }\end{array}$ & $\begin{array}{l}\text { 1. Provide reliable information on the risk, severity, and progression } \\
\text { of a pandemic and the effectiveness of interventions used; } \\
\text { 2. Provide health care; } \\
\text { 3. Reduce the spread of influenza; } \\
\text { 4. Protect and support health-care workers. }\end{array}$ & \\
\hline \multicolumn{2}{|c|}{ Business Sectors } & & $\begin{array}{l}\text { 1. Medical supplies and services; } \\
\text { 2. Monitor absenteeism; } \\
\text { 3. Reduce population density in shopping areas; } \\
\text { 4. Protect employees; } \\
\text { 5. Provide accurate and timely communication } \\
\text { messages; } \\
\text { 6. Provide personal protective equipment and } \\
\text { training }\end{array}$ \\
\hline \multicolumn{2}{|c|}{$\begin{array}{l}\text { Civil society and community- } \\
\text { based organizations }\end{array}$} & $\begin{array}{l}\text { 1. Translate scientific and government messages and recommendations; } \\
\text { 2. Build public confidence, disseminate information, and identify people } \\
\text { at risk; } \\
\text { 3. Provide community-based services }\end{array}$ & 1. Maintain or expand their essential services \\
\hline \multicolumn{2}{|c|}{ Individuals and families } & $\begin{array}{l}\text { 1. For families, have access to reliable information from sources; } \\
\text { 2. For individuals, assist the others; } \\
\text { 3. Adoption of individual and household measures, such as } \\
\text { covering coughs and sneezes, hand washing, and the voluntary } \\
\text { isolation of persons with respiratory illness }\end{array}$ & \\
\hline
\end{tabular}

\footnotetext{
World Health Organization. Pandemic Influenza Preparedness and Response, 2009

${ }^{\mathrm{b}}$ World Health Organization. Pandemic Influenza Risk Management, 2013
}

c World Health Organization. Pandemic Influenza Risk Management, 2017 


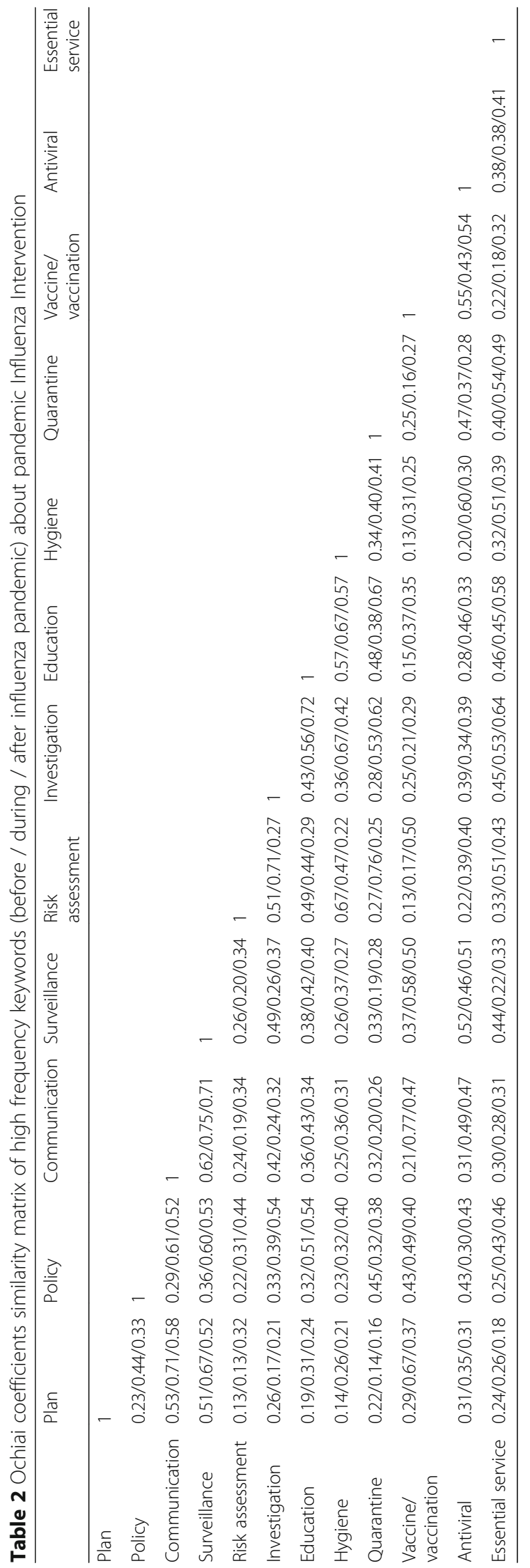


Table 3 Assessment theme and the content for the prevention and control of the pandemic influenza

\begin{tabular}{|c|c|}
\hline Assessment Theme & Details \\
\hline Assessment of pandemic severity & $\begin{array}{l}\text { 1. Transmissibility: virological factors and epidemiological observations; } \\
\text { 2. Seriousness of disease; } \\
\text { 3. Impact: socioeconomic impact [5]. }\end{array}$ \\
\hline Risk assessment & $\begin{array}{l}\text { 1. Hazard assessment: identifying, reviewing and ranking influenza viruses of concern; } \\
\text { 2. Exposure assessment: epidemiological and susceptibility factors; } \\
\text { 3. Context assessment: social, technological and scientific, economic, ethical, and } \\
\text { policy and political factors; } \\
\text { 4. Risk characterization [5]. }\end{array}$ \\
\hline Assessment of national planning & $\begin{array}{l}\text { 1. Planning and coordination; } \\
\text { 2. Situation monitoring and assessment; } \\
\text { 3. Prevention and containment; } \\
\text { 4. Health system response; } \\
\text { 5. Communication [27]. }\end{array}$ \\
\hline Simulation exercises on influenza pandemic responses & $\begin{array}{l}\text { 1. Orientation: an informal discussion designed to familiarize participants with } \\
\text { plans, roles and procedures with a focus on questions of coordination and } \\
\text { assignment of responsibilities; } \\
\text { 2. Drill: developing and maintaining skills in a single response procedure; } \\
\text { 3. Table-top exercise (TTX): a discussion held around a conference or round } \\
\text { table over the space of } 2 \text { or } 3 \text { h; } \\
\text { 4. Functional exercise: creating a situation and facilitating a 'real' response, and } \\
\text { may include such activities as activating command centres, documenting actions } \\
\text { and decisions, completing real forms, issuing real communications and responding } \\
\text { to simulated media or other questions; } \\
\text { 5. Full-scale exercise: focusing on the operational capability of emergency response } \\
\text { and management systems [29]. }\end{array}$ \\
\hline Effectiveness of public health measures & $\begin{array}{l}\text { 1. Economic effects; } \\
\text { 2. Influenza-like illness(ILI), hospitalization rates or laboratory-confirmed cases, } \\
\text { incidence rate ratios; } \\
\text { 3. Change of behavior [30]. }\end{array}$ \\
\hline
\end{tabular}

version of 2013 and 2017. The nation-level financial planning and emergency funding mechanisms for pandemic influenza was added for ministries of finance in the version of 2013 and 2017. Because of the urgency and complexity of the pandemic $\mathrm{H} 1 \mathrm{~N} 1$ situation, a flexible financing framework embracing a variety of funding mechanisms was proposed as the best means of providing financial support to least resourced countries $[13,14]$. Participating countries were seeking support to enable them to strengthen their readiness and response to $\mathrm{H} 1 \mathrm{~N} 1$ pandemic influenza. Capacity development is central to ensure that the workforce is well equipped to implement influenza response planning. Thus, funding and training are crucial to a national pandemic preparedness plan [5].

It has been proved in the global polio eradication action that the effectiveness of technology depends on national political commitment, security assurance, social support, religious support, local public support, project management and community participation $[15,16]$. Influenza pandemic preparedness strategies and polio eradication plan share many common aspects, including extensive surveillance and laboratory networks, preparedness and response to epidemics, extensive communication, social mobilization networks and etc. As expected, the results of the present study provide some hints or experience of the prevention and control of pandemic influenza.

There have been some studies focusing on the intervention of pandemic influenza, such as communication, vaccination coverage, gas mask distribution, public health surveillance, knowledge and practices of intervention [17-26], while the correlations among these interventions were not discussed sufficiently. As the influenza control measures were different across pandemic influenza and the internal links between the measures are vague, the research adopted a word frequency analysis to explore the linkage of various influenza control measures. Information communication and disease surveillance provide essential disease information for better planning and decision making, which has been clearly indicated by the Ochiai coefficients. The higher correlations between the word frequencies after the pandemic influenza suggested that the relationships among the various measures were emphasized.

Assessment is an important part of pandemic influenza preparedness, which cannot be ignored. Early and comprehensive information on the severity of an influenza pandemic and risk assessment can help support decision-making at global and country levels. The five aspects of assessment of national planning have been identified as planning and coordination, situation 
monitoring and assessment, prevention and containment, health system response and communication [27]. A good planning requires simulation exercises to ensuring the feasibility of the plan [28]. WHO has provided 5 kinds of simulation exercises, each of them having strengths and weakness. Of the five types of exercises, an orientation is the simplest and costs the least, while the table-top exercise (TTX) is the workhorse, ranging in scope and complexity. The full-scale exercise is the most comprehensive also the most cost one [29]. Decision makers can choose the most suitable one according to their situation. Referring to effectiveness of public health measures, it is also difficult to evaluate the effectiveness of individual measures because it was difficult to determine what to measure and it often combined with other interventions [30].

There are several limitations in the present study which may encourage further research efforts. Firstly, although the correlations between the word frequencies of influenza control-related vocabularies in the included documents were analyzed, the interaction of different preventive measures could not be identified. Better understanding the role of each preventive measures in the influenza control network will be considered in our future work. Secondly, the included influenza control-related measures were summarized from the documents released by international organizations, however, the implementation of these measures in the real world is unknown. There will be no response if funds are not set aside for rapid and proper action, moreover, personnel who are properly trained are needed. The governments should plan this and set aside special pandemic influenza preparedness budget when they prepare their yearly budget. Cost-benefit analysis may help to provide some evidence in the future. Thirdly, different experts were invited by each international organization according to its own interest to provide their opinions about pandemic influenza preparedness. WHO is concerned with human health, FAO and OIE are concerned with animal health, while the World Bank is more concerned with the economic losses caused by the disease. Different main focus of these international organizations affected the content and article length of the documents regarding pandemic influenza preparedness. Fourth, the present bibliometric analysis focused on the official documents released by international organizations, and the documents released by WHO were treated as the gold standard. However, the choice of WHO text was also a kind of limitation, because pandemic influenza preparedness varied in different situations. For example, the US government has its own national implementation plan for pandemic influenza [31]. In terms of evaluation, a literature review by Arin Dutta provided a comprehensive description on determinants of a pandemic influenza outbreak, the effectiveness of different policies, cost and cost-effectiveness of policies and ethical dimensions of pandemic control policies [32]. Fifth, the phase during 2009 influenza pandemic was shorter than the other two phases before and after pandemic, which might cause the amount of those documents during the pandemic period was relatively smaller than those released in the other two periods, thus, the result of the word frequency analysis might be affected. Finally, the actual work was done 12 years earlier than the publication date of the included documents, which might mislead the assessment of the changes over time in the documents.

\section{Conclusions}

Responsibilities of ministries of education, ministries of energy, ministries of agriculture and animal health, ministries of communication and the business sector in the pandemic influenza preparedness were described more comprehensively in the international organizations' documents in 2017. Better understanding the variations of the guidelines delivered by international organizations would be useful for the member countries to strengthen their influenza control network.

\section{Additional file}

Additional file 1: Table S1. Basic information of the included documents about pandemic influenza preparedness from international organization websites. (DOCX $30 \mathrm{~kb}$ )

\section{Abbreviations}

ADPC: Asia-Pacific Regional Hub in collaboration with Asian Disaster Preparedness Center; AFP: Acute delayed paralysis; FAO: Food and Agriculture Organization of the United Nations; GPLN: Global polio laboratory network; GTZ: The German Technical Cooperation; ICAO: International Civil Aviation Organization; ILI: Influenza-like illness; ILO: International Labour Organization; IOM: International Organization for Migration; K. I. Asia: Kenan Institute Asia; OCHA: Office for the Coordination of Humanitarian Affairs; OlE: World Organization for Animal Health; TTX: Table-top exercise; UNDP: United Nations Development Programme; UNFPA: United Nations Population Fund; UNHCR: United Nations High Commissioner for Refugees; UNICEF: United Nations Children's Fund; UNSIC: United Nations System Influenza Coordinator; UNWTO: World Tourism Organization; WFP: World Food Programme; WHO: World Health Organization

\section{Acknowledgements \\ This study is based in part on the information from the documents provided by World Health Organization, the World Bank, UN System Influenza Coordination Office (UNSIC). \\ Funding \\ This work is supported by the National Natural Science Foundation of China (NNSFC, Grant No. 71573275). The funding source had no role in the study design, data collection, analysis and interpretation, or in the writing of this manuscript.}

\section{Availability of data and materials}

All data generated or analyzed during this study are included in this published article and its supplementary information files (Table S1). The documents included in the present study are also available from the corresponding author on request. 


\section{Authors' contributions}

FL participated in the data collections, statistical analysis and drafted the manuscript. DSH provided overall leadership to the study, participated in the analysis and secured funding. PG participated in the design, statistical analysis and assisted in drafting the manuscript. WW, JL, NZ and BSZ participated in the data collection and discussion. All authors have read and approved the final manuscript

\section{Ethics approval and consent to participate}

Not applicable.

\section{Consent for publication}

Not applicable.

\section{Competing interests}

The authors declare that they have no competing interests.

\section{Publisher's Note}

Springer Nature remains neutral with regard to jurisdictional claims in published maps and institutional affiliations.

\section{Received: 31 October 2017 Accepted: 31 July 2018}

Published online: 08 August 2018

\section{References}

1. Black AJ, Geard N, McCaw JM, McVernon J, Ross JV. Characterising pandemic severity and transmissibility from data collected during first few hundred studies. Epidemics. 2017;19:61-73. https://doi.org/10.1016/j.epidem. 2017.01.004.

2. World Health Organization. Evolution of a pandemic: a(H1N1) 2009, April 2009 - august 2010 - 2nd ed. Geneva: World Health Organization; 2013. http://apps.who.int/iris/bitstream/10665/78414/1/9789241503051_eng. pdf?ua=1. Accessed 3 July 2017

3. World Health Organization. Pandemic (H1N1) 2009 - update 76; 2009. www. who.int/csr/don/2009_11_27a/en/index.html. Accessed 3 July 2017.

4. World Health Organization. Pandemic (H1N1) 2009. Update 81; 2009. www. who.int/csr/don/2009 12 30/en/index.html. Accessed 3 July 2017.

5. World Health Organization. Pandemic Influenza Risk Management. Geneva: World Health Organization; 2017. http://www.who.int/influenza/preparedness/ pandemic/PIRM_update_052017.pdf?ua=1. Accessed 3 July 2017

6. World Health Organization. Pandemic Influenza Risk Management. Geneva: World Health Organization; 2013. http://www.who.int/influenza/preparedness/ pandemic/GIP_PandemiclInfluenzaRiskManagementInterimGuidance_Jun2013. pdf?ua=1. Accessed 3 July 2017

7. World Health Organization. Pandemic influenza preparedness and response. Geneva: World Health Organization; 2009. http://apps.who.int/iris/bitstream/ 10665/44123/1/9789241547680_eng.pdf?ua=1. Accessed 3 July 2017

8. Johnson LE, Clara W, Gambhir M, Chacon-Fuentes R, Marin-Correa C, Jara J, Minaya P, Rodriguez D, Blanco N, lihoshi N, et al. Improvements in pandemic preparedness in 8 Central American countries, 2008-2012. BMC Health Serv Res. 2014;14:209. https://doi.org/10.1186/1472-6963-14-209.

9. Iskander J, Strikas RA, Gensheimer KF, Cox NJ, Redd SC. Pandemic influenza planning, United States, 1978-2008. Emerg Infect Dis. 2013;19(6):879-85. https://doi.org/10.3201/eid1906.121478.

10. Hanvoravongchai P, Adisasmito W, Chau PN, Conseil A, de Sa J, Krumkamp R, Mounier-Jack S, Phommasack B, Putthasri W, Shih CS, et al. Pandemic influenza preparedness and health systems challenges in Asia: results from rapid analyses in 6 Asian countries. BMC Public Health. 2010;10:322. https:// doi.org/10.1186/1471-2458-10-322.

11. World Health Organization. Whole-of-society pandemic readiness. Geneva: World Health Organization; 2009. http://www.who.int/influenza/ preparedness/pandemic/2009-0808_wos_pandemic_readiness_final.pdf?ua= 1. Accessed 3 July 2017

12. Gupta MD, Dalpatadu KCS, Shanmugarajah CK, Herath HMSS. Multisectoral preventive health Services in Sri Lanka : lessons for developing countries in providing public goods in health. Washington, DC: the World Bank; 2013. https:/openknowledge.worldbank.org/bitstream/handle/10986/21475/ WPS6558.pdf? sequence $=1$ \&isAllowed=y. Accessed 3 July 2017

13. World Health Organization, United Nations Office for the Coordination of Humanitarian Affairs, United Nations System Influenza Coordinator. Urgent Support for Developing Countries' Responses to the H1N1 Influenza
Pandemic; 2010. http://www.un-influenza.org/sites/default/files/ June2010UNIPReportFINAL.pdf. Accessed 3 July 2017.

14. World Health Organization, United Nations Office for the Coordination of Humanitarian Affairs, United Nations System Influenza Coordinator. Urgent Support for Developing Countries' Responses to the H1N1 Influenza Pandemic; 2010. http://www.un-influenza.org/sites/default/files/ FinalUNIPReportMarch2010.pdf. Accessed 3 July 2017.

15. Luo HM, Zhang Y, Wang XQ, Yu WZ, Wen N, Yan DM, Wang HQ, Wushouer $F$, Wang $H B$, Xu AQ, et al. Identification and control of a poliomyelitis outbreak in Xinjiang, China. N Engl J Med. 2013;369(21):1981-90. https://doi. org/10.1056/NEJMoa1303368.

16. Aylward B, Tangermann R. The global polio eradication initiative: lessons learned and prospects for success. Vaccine. 2011;29(Suppl 4):D80-5. https:// doi.org/10.1016/j.vaccine.2011.10.005.

17. Determann D, de Bekker-Grob EW, French J, Voeten HA, Richardus JH, Das E, Korfage IJ. Future pandemics and vaccination: public opinion and attitudes across three European countries. Vaccine. 2016;34(6):803-8. https:// doi.org/10.1016/j.vaccine.2015.12.035.

18. Huang QS, Turner N, Baker MG, Williamson DA, Wong C, Webby R, Widdowson MA. Southern hemisphere influenza and vaccine effectiveness research and surveillance. Influenza Other Respir Viruses. 2015:9(4):179-90. https://doi.org/10.1111/irv.12315.

19. Shi J, Njai R, Wells E, Collins J, Wilkins M, Dooyema C, Sinclair J, Gao H, Rainey JJ. Knowledge, attitudes, and practices of nonpharmaceutical interventions following school dismissals during the 2009 influenza A H1N1 pandemic in Michigan, United States. PLoS One. 2014;9(4):e94290. https:// doi.org/10.1371/journal.pone.0094290

20. Heo JY, Chang SH, Go MJ, Kim YM, Gu SH, Chun BC. Risk perception, preventive behaviors, and vaccination coverage in the Korean population during the 2009-2010 pandemic influenza A (H1N1): comparison between high-risk group and non-high-risk group. PLoS One. 2013;8(5):e64230. https://doi.org/10.1371/journal.pone.0064230.

21. Velan B, Boyko V, Shenhar G, Lerner-Geva L, Kaplan G. Analysis of public responses to preparedness policies: the cases of $\mathrm{H} 1 \mathrm{~N} 1$ influenza vaccination and gas mask distribution. Isr J Health Policy Res. 2013;2(1):11. https://doi. org/10.1186/2045-4015-2-11.

22. Agolory SG, Barbot O, Averhoff F, Weiss D, Wilson E, Egger J, Miller J, Ogbuanu I, Walton S, Kahn E. Implementation of non-pharmaceutical interventions by New York City public schools to prevent 2009 influenza A. PLoS One. 2013;8(1):e50916. https://doi.org/10.1371/journal.pone.0050916.

23. Stoto MA. The effectiveness of U.S. public health surveillance systems for situational awareness during the $2009 \mathrm{H} 1 \mathrm{~N} 1$ pandemic: a retrospective analysis. PLoS One. 2012;7(8):e40984. https://doi.org/10.1371/journal.pone. 0040984.

24. Boyd CA, Gazmararian JA, Thompson WW. Knowledge, attitudes, and behaviors of low-income women considered high priority for receiving the novel influenza A (H1N1) vaccine. Matern Child Health J. 2013;17(5):852-61. https://doi.org/10.1007/s10995-012-1063-2.

25. Schlaich C, Gau B, Cohen NJ, Kojima K, Marano N, Menucci D. Infection control measures on ships and in ports during the early stage of pandemic influenza A (H1N1) 2009. Int Marit Health. 2012:63(1):17-23.

26. Sonthichai C, lamsirithaworn S, Cummings D, Shokekird P, Niramitsantipong A, Khumket S, Chittaganpitch M, Lessler J. Effectiveness of non-pharmaceutical interventions in controlling an influenza A outbreak in a school, Thailand, November 2007. Outbreak Surveill Investig Rep. 2011;4(2):611.

27. World Health Organization. Comparative analysis of national pandemic influenza preparedness plans. Geneva: World Health Organization; 2011. http://www.who.int/influenza/resources/documents/comparative_analysis_ php_2011_en.pdf?ua=1. Accessed 3 July 2017

28. World Health Organization. Considerations on exercises to validate pandemic preparedness plans. Geneva: World Health Organization. http:// www.who.int/influenza/resources/documents/ExerciseConsiderations.pdf. Accessed 3 July 2017.

29. United Nations System Influenza Coordinator, Asia-Pacific Regional Hub in collaboration with Asian Disaster Preparedness Center, Kenan Institute Asia. Simulation exercises on influenza pandemic responses in the AsiaPacific region. New York: UN System Influenza Coordination Office (UNSIC); 2008. http://un-influenza.org/sites/default/files/unsic_pandemic_ complete.pdf

30. World Health Organization. Public health measures during the influenza A(H1N1)2009 pandemic. Geneva: World Health Organization; 2011. http:// 
apps.who.int/iris/bitstream/10665/70747/1/WHO_HSE_GIP_ITP_2011.3_eng. pdf. Accessed 3 July 2017

31. Homeland Security Council. Pandemic Influenza Implementation Plan. Washington DC. The white house. https://www.cdc.gov/flu/pandemicresources/pdf/pandemic-influenza-implementation.pdf. Accessed 2 June 2018.

32. Dutta A. The effectiveness of policies to control a human influenza pandemic: a literature review. Washington, DC: the World Bank; 2008. https://openknowledge.worldbank.org/bitstream/handle/10986/6397/ wps4524.pdf?sequence=1\&isAllowed=y. Accessed 3 July 2017

- fast, convenient online submission

- thorough peer review by experienced researchers in your field

- rapid publication on acceptance

- support for research data, including large and complex data types

- gold Open Access which fosters wider collaboration and increased citations

- maximum visibility for your research: over $100 \mathrm{M}$ website views per year

At BMC, research is always in progress.

Learn more biomedcentral.com/submissions 